\title{
COVID-19 and Malaria: A Fatal Attraction for SARS CoV-2?
}

\author{
Randall E Harris ${ }^{1, *}$ and Alexander S Rosemurgy ${ }^{2}$ \\ ${ }^{1}$ Colleges of Medicine \& Public Health, The Ohio State University, Ohio, USA \\ ${ }^{2}$ Digestive Health Institute, Advent Health Tampa, Florida, USA
}

*Corresponding author: Randall E Harris, Colleges of Medicine \& Public Health, The Ohio State University, Ohio, USA, Tel: 43210-1351; E-mail: Harris.44@osu.edu

Received: 11 Jun, 2020 | Accepted: 22 Jun, 2020 | Published: 26 Jun, 2020

Citation: Harris RE, Rosemurgy AS (2020) COVID-19 and Malaria: A Fatal Attraction for SARS CoV-2? J Epidemiol Public Health Rev 5(2): dx.doi.org/10.16966/2471-8211.194

Copyright: @ 2020 Harris RE, et al. This is an open-access article distributed under the terms of the Creative Commons Attribution License, which permits unrestricted use, distribution, and reproduction in any medium, provided the original author and source are credited.

\begin{abstract}
We examined trends and differences in the average cumulative rates of COVID-19 cases and deaths per million (incidence and mortality rates) among 11 Asian nations where malaria is endemic (China, Hong Kong, South Korea, Thailand, Vietnam, Cambodia, India, Pakistan, Malaysia, Indonesia and the Philippines) and compared these trends and differences to 11 western nations (United States, Canada, Great Britain, Spain, Italy, Germany, France, Portugal, Netherlands, Switzerland and Austria) during the five month period, 1/1/2020-5/31/2020. The mean rates of incidence and mortality for the two sets of countries diverge markedly and as of May 31, 2020, the incidence and mortality rates for Asian countries (130 per million and 3.6 per million, respectively) were $1 / 27^{\text {th }}$ and $1 / 89^{\text {th }}$ of the corresponding rates for North American and Western European countries $(3,481$ per million and 321 per million). In contrast, annual incidence rates of malaria are negligible in North America and Europe whereas malaria is endemic in Southeast Asia $(3.5$ per 1,000). Chronic infections by malarial plasmodia induce interferons and neutralizing antibodies with proven impact against infection by the corona viruses responsible for SARS, MERS and COVID-19. Therefore, there may be natural immunity against infection by SARS CoV-2 in populations that have a longstanding history of widespread exposure to malarial infections. Such populations may be a valuable resource for development of effective vaccines and serological agents for the prevention and therapy of COVID-19.
\end{abstract}

Keywords: SARS CoV-2; COVID-19; Malaria; Interferons; Neutralizing Antibodies; Incidence; Mortality

\section{Introduction}

In a preliminary study, we found huge differences in the mean incidence and mortality of COVID-19 between countries of South Asia versus those in North America and Western Europe [1]. As of May 4, 2020, the average incidence rate (83.7 per million) and the average mortality rate (2.24 per million) in 11 Asian countries were approximately $1 / 34^{\text {th }}$ and $1 / 118^{\text {th }}$, respectively, of the corresponding values reported by countries in North America and Europe $(2,878$ per million and 265 per million, respectively). In contrast, the annual incidence of endemic malaria shows the reciprocal pattern: rates are negligible in North America and Europe and relatively high in Southeast Asia.

In this report, we examined patterns of SARS CoV-2 infections in countries of each of these regions and the reciprocal pattern in the annual incidence rates of malaria. Our results are current to May 31, 2020.

\section{Methods}

Methods were similar to our initial epidemiologic study [1]. We abstracted rates of tests for COVID-19 infection, rates of positive tests (unadjusted incidence rates), and COVID-19 death rates (unadjusted mortality rates) for eleven Southeastern Asia countries (China, Hong
Kong, South Korea, Thailand, Vietnam, Cambodia, India, Pakistan, Malaysia, Indonesia and the Philippines) from the Worldometers website [2] for comparison with eleven countries of North America and Europe (United States, Canada, Great Britain, Spain, Italy, Germany, France, Portugal, Netherlands, Switzerland and Austria). Asian countries were selected due to their proximity to the epicenter of the COVID-19 pandemic in Wuhan, China. Means of the rates for each set of countries were calculated with $95 \%$ confidence intervals and mean differences checked for statistical significance by t-tests. We also estimated crude case fatality rates for each country (unadjusted case fatality=death rate/case rate) and tested the difference in mean case fatality for each set of countries. Mean rates for the Asian and Western countries were computed at weekly time intervals during $3 / 1 / 2020-5 / 31 / 2020$ and plotted over time. Trends and differences in weekly rates were modeled by fitting $S$ curves to the data using the logistic function.

\section{Results}

The mean incidence and mortality rates reported for COVID-19 show a sharp divergence in countries of Southeastern Asia compared to North America and Europe. As shown in the table 1, the average incidence rate of cases (130.4 per million) and the average mortality rate (3.6 per million) in the Asian countries through May 31, 2020, 
were approximately $1 / 27^{\text {th }}$ and $1 / 89^{\text {th }}$, respectively, of the corresponding values reported by countries in North America and Europe (3,480 per million and 321 per million, respectively, $\mathrm{P}<0.001)$. For these same countries, the average frequency of positive tests among all tests for COVID-19 in Asia (1.76\%) was $74 \%$ less than the corresponding frequency $(6.85 \%)$ in North America and Europe $(\mathrm{P}<0.01)$. Similarly, the mean case fatality among Asian countries (2.76\%) was $70 \%$ less than the corresponding estimate (9.22\%) for countries of North America and Europe $(\mathrm{P}<0.01)$. Since China did not report the number of tests conducted, we also calculated rates and differences with the China data excluded, but found little change in the results (Table 1).

The Table also includes recently reported annual incidence rates of malaria for the countries of North America and Europe versus Southeast Asia [3]. Clearly, the incidence rates of malaria are inversely related to the incidence and mortality of COVID-19, e.g., COVD19 rates are relatively high and malaria rates are negligible in North America and Europe whereas COVID-19 rates are relatively low and malaria rates high in Southeastern Asia.

Figure 1 shows the trends and marked differences in the mean COVID-19 mortality rates for the 11 countries of Southeastern Asia versus those of North America and Europe during 4/1/2020-5/31/2020. Note that in order to plot these rates on the same chart, the rates for the countries of Southeastern Asia were expressed per 10 million whereas rates for the countries of North America and Europe were expressed per million. Throughout the time period covered, the average mortality rate for the countries of North America and Europe was approximately 90-fold higher than the countries of Southeastern Asia. Based on the best fitting logistic functions ( $\mathrm{S}$ curves) shown in Figure 1 for each set of data, the mean COVID-19 mortality is projected to maximize at approximately 60 per 10 million for the Asian nations and 350 per million for the North American and Western European nations by the end of June, 2020.

\section{Discussion and Conclusion}

Our results show marked divergence in the incidence and mortality of COVID-19 between Southeastern Asian countries and North American/Western European countries. Malaria is endemic in those nations with low rates of COVID-19 but is negligible in nations with high rates of COVID-191.The difference in mortality is particularly striking as COVID-19 death rates are approximately 90 -fold higher in non-endemic nations compared to those that are endemic for malaria.

Other investigators have also begun to examine COVID-19 rates in countries endemic for malaria compared to non-endemic countries. Early preprints and preliminary reports of these studies are in

Table 1: Cumulative COVID-19 rates compared to the incidence of malaria in countries of Southeastern Asia, North America and Europe, 12/01/2020$5 / 31 / 2020$.

\begin{tabular}{|c|c|c|c|c|}
\hline Country & COVID-19 Tests/M & COVID-19 Cases/M & COVID-19 Deaths/M & Malaria Cases Incidence/1,000 \\
\hline \multicolumn{5}{|c|}{ North American \& European Countries } \\
\hline United States & 52,326 & 5,501 & 319 & 0 \\
\hline Canada & 43,334 & 2,391 & 188 & 0 \\
\hline Italy & 63,249 & 3,848 & 551 & 0 \\
\hline Spain & 76,071 & 6,124 & 580 & 0 \\
\hline Germany & 47,193 & 2,189 & 103 & 0 \\
\hline France & 21,217 & 2,890 & 441 & 0 \\
\hline Portugal & 78,030 & 3,187 & 138 & 0 \\
\hline Great Britain & 61,474 & 4,021 & 566 & 0 \\
\hline Netherlands & 20,380 & 2,711 & 348 & 0 \\
\hline Switzerland & 45,980 & 3,568 & 222 & 0 \\
\hline Austria & 49,826 & 1,859 & 74 & 0 \\
\hline $\begin{array}{l}\text { Mean } \\
(95 \% \mathrm{Cl})\end{array}$ & 50,825 & $\begin{array}{c}3,481 \\
(2,649-4,312)\end{array}$ & $\begin{array}{c}321 \\
(203-439)\end{array}$ & 0 \\
\hline \multicolumn{5}{|c|}{ Southeastern Asian Countries } \\
\hline China & 580 & 58 & 3 & $<0.1$ \\
\hline Hong Kong & 27,087 & 145 & 0.5 & $<0.1$ \\
\hline South Korea & 17,767 & 224 & 5 & $<0.1$ \\
\hline Malaysia & 17,111 & 242 & 4 & 0.1 \\
\hline Philippines & 3,176 & 165 & 9 & 0.3 \\
\hline Pakistan & 2,481 & 315 & 7 & 4.9 \\
\hline Thailand & 5,380 & 44 & 0.8 & 0.8 \\
\hline Viet Nam & 2,827 & 3 & 0.1 & 0.1 \\
\hline Cambodia & 1,222 & 7 & 0.2 & 18.4 \\
\hline Indonesia & 1,183 & 97 & 6 & 5.8 \\
\hline India & 2,710 & 135 & 4 & 7.7 \\
\hline $\begin{array}{l}\text { Mean } \\
(95 \% \mathrm{Cl})\end{array}$ & 7,411 & $\begin{array}{c}130.5 \\
(68-193)\end{array}$ & $\begin{array}{c}3.60 \\
(1.7-5.5)\end{array}$ & $\begin{array}{c}3.5 \\
(0.2-6.8)\end{array}$ \\
\hline $\begin{array}{l}\text { Excl. China } \\
(95 \% \text { Cl) }\end{array}$ & 8,094 & $\begin{array}{c}134.7 \\
(70-205)\end{array}$ & $\begin{array}{c}3.66 \\
(1.6-5.7)\end{array}$ & $\begin{array}{c}3.8 \\
(0.2-7.4)\end{array}$ \\
\hline
\end{tabular}

Citation: Harris RE, Rosemurgy AS (2020) COVID-19 and Malaria: A Fatal Attraction for SARS CoV-2? J Epidemiol Public Health Rev 5(2): 


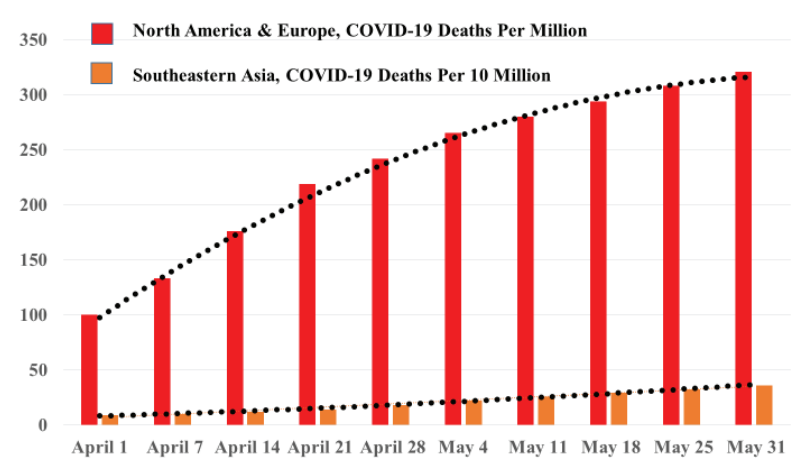

Figure 1: Mean COVID-19 mortality in countries of Southeastern Asia versus North America and Europe, 4/1/2020-5/31/2020.

agreement with our findings indicating that malaria-free populations have markedly higher rates of COVID-19 than nations plagued by endemic malaria [4-7].

One hypothesis advanced to explain the low COVID-19 rates in populations' endemic for malaria is their widespread use of antimalarial drugs that have anti-viral effects. For example, some studies have found that the anti-malarial agent, Hydroxychloroquine (HCQ), has therapeutic benefit for patients with COVID-19 [8]. Since this relatively inexpensive anti-malarial drug was widely used for many decades in the geographic hot zones of malaria in Southeast Asia, it has been suggested that HCQ may have current chemopreventive impact against novel viral infections such as SARS CoV-2 [4,5]. However, due to the evolvement of chloroquine-resistant strains of malarial plasmodia, HCQ prophylaxis has largely been replaced by other more effective drugs and HCQ is not currently in widespread use in the general populations of these nations [9]. Furthermore, HCQ is a zinc ionophore, and the anti-viral effects of HCQ are primarily due to the intracellular inhibition of viral replication by zinc ions [10]. Since a large portion of South Asian populations suffer from zinc deficiency [11], it is therefore unlikely that HCQ would be an effective chemopreventive agent against SARS CoV-2 in these populations.

A more likely hypothesis is that repeat malarial infections that are widespread in South Asian populations create immunocompetence not only against malaria, but also against novel viral infections. It is well known that malaria induces interferons with proven impact against infection by certain viruses. Molecular studies from multiple laboratories have found that interferons released by lymphocytes is a normal immune response to infection by multiple strains of malaria, and that these same interferons have both in vitro and in vivo effects against the coronaviruses responsible for SARS, MERS and COVID-19 [12-15]. Repeat malarial infections also induce the development of persisting antibodies that neutralize a broad profile of merozoite antigens, and neutralizing antibodies have recently been noted to have effects against SARS CoV-2 and other coronaviruses [16,17].

While it can be argued that the inverse association of COVID-19 and malaria may primarily reflect disparities in demographics, testing, reporting, and infection control, the potential for biological effects must also be considered. The epidemiological data characterizing the current COVID-19 pandemic combined with the international pattern of malaria and molecular findings regarding the long term immune impact of repeat malarial infections can be interpreted to support the hypothesis that there may be natural immunity against COVID-19 in populations that have a longstanding history of widespread exposure and acquired natural immunity to malarial infections. Specifically, the majority of individuals in these populations may have high levels of circulating interferons, neutralizing antibodies, and other factors that enable them to mount rapid and effective immune responses to novel viral infections. Such populations with natural resistance to SARSCoV-2 infection may prove to be a valuable resource for serological factors as well as the development of vaccines and drugs for the effective prevention and therapy of COVID-19.

\section{Competing Interests}

The authors declare that they have no competing interests.

\section{References}

1. Harris RE, Rosemurgy AS (2020) Inverse Association of COVID-19 and malaria: Natural Immunity to SARS CoV-2 infection? Microbiol Infect Dis 4: 1-3.

2. COVID-19 Coronavirus Pandemic (2020) Worldometer.

3. Roser M, Ritchie H (2020) Malaria. Our World in Data, England.

4. Mitchell G, Khuder S (2020) Markedly lower rates of coronavirus infection and fatality in malaria-endemic regions-a clue as to treatment? Social Science Research Network 1-13.

5. Adams D, Alshaban F (2020) COVID-19 cases are less prevalent in countries where malaria is endemic, suggesting a role for antimalarial drugs as prophylaxis. Eye Reports 6: S11-S16.

6. Muneer A, Kumari K, Tripathi M, Srivastava R, Mohmmed A, et al. (2020) Comparative analyses revealed reduced spread of COVID-19 in malaria endemic countries. medRXiv.

7. Ahmed AE (2020) Incidence of Coronavirus Disease (COVID-19) and Countries Affected by Malarial Infections. Travel Med Infect Dis 101693.

8. Gautret P, Lagier JC, Parola P, Hoang VT, Meddeb L, et al. (2020) Hydroxychloroquine and Azithromycin as a Treatment of COVID-19: Results of an Open-Label Non-Randomized Clinical Trial. Int J Antimicrob Agents 105949.

9. Castelli F, Odolini S, Autino B, Foca E, Russo R (2010) Malaria Prophylaxis: A Comprehensive Review. Pharmaceuticals (Basel) 3: 3212-3239.

10. Xue J, Moyer A, Peng B, Wu J, Hannafon BN, et al. (2014) Chloroquine Is a zinc ionophore. PLoS One 9: e109180.

11. Akhtar S (2013) Zinc Status in South Asian Populations--An Update. J Health Popul Nutr 31: 139-149.

12. King T, Lamb T (2015) Interferon- $\gamma$ : The Jekyll and Hyde of Malaria. PLoS Pathog 11: e1005118.

13. Strayer DR, Dickey R, Carter WA (2014) Sensitivity of SARS/MERS CoV to Interferons and Other Drugs based on Achievable Serum Concentrations in Humans. Infect Disord Drug Targets 14: 37-43.

14. Mehta P, McAuley DF, Brown M, Sanchez E, Tattersall RS, et al. (2020) COVID-19: Consider Cytokine Storm Syndromes and Immunosuppression. The Lancet 395: 1033-1034.

15. Fauci AS, Lane HC, Redfield RR (2020) COVID-19-Navigating the Uncharted. N Engl J Med 382: 1268-1269.

16. Jiang S, Hillyer C, Du L (2020) Neutralizing Antibodies against SARSCoV-2 and Other Human Coronaviruses. Trends in Immunol 41: 355359.

17. Corti D, Lanzavecchia A (2013) Broadly neutralizing antiviral antibodies. Annu Rev Immunol 31: 705-742. 